\title{
2002 White Paper on Pharmacy Technicians Needed Changes Can No Longer Wait
}

\begin{abstract}
The counting and pouring now often alleged to be the pharmacist's chief occupation will in time be done by technicians and eventually by automation. The pharmacist of tomorrow will function by reason of what he knows, increasing the efficiency and safety of drug therapy and working as a specialist in his own right. It is in this direction that pharmaceutical education must evolve without delay.
\end{abstract}

Linwood F. Tice, D. Sc., Dean, Philadelphia College of Pharmacy and Science (1966) ${ }^{1}$

Editor's Note

The "2002 White Paper on Pharmacy Technicians: Needed Changes Can No Longer Wait," endorsed by the Council on Credentialing in Pharmacy, is being printed in its entirety (with an abridged appendix), without alteration. It is being printed simultaneously in a number of journals.

\section{Introduction}

Health care and the profession of pharmacy have changed enormously since Dr. Tice articulated this vision more than 35 years ago. The role of the pharmacy technician has likewise undergone substantial change. Technicians have increased in number. They may access a wide array of training opportunities, some of which are formal academic programs that have earned national accreditation. Technicians may now seek voluntary national certification as a means to demonstrate their knowledge and skills. State boards are increasingly recognizing technicians in their pharmacy practice acts.

Nonetheless, Dr. Tice's vision remains unrealized. Although pharmacy technicians are employed widely in all pharmacy practice settings, their qualifications, knowledge, and responsibilities are markedly diverse. Their scope of practice has not been sufficiently examined. Basic competencies have not been articulated. Standards for technician training programs are not widely adopted. Board regulations governing technicians vary substantially from state to state.

Is there a way to bring greater uniformity in technician competencies, education, training, and regulation while ensuring that the technician workforce remains sufficiently diverse to meet the needs and expectations of a broad range of practice settings? This is the question that continues to face the profession of pharmacy today as it seeks to fulfill its mission to help people make the best use of medications.

The purpose of this paper is to set forth in context the issues that must be resolved in order to promote the development of a strong and competent pharmacy technician workforce. Helping pharmacists to fulfill their potential, as providers of pharmaceutical care, would be one of many positive outcomes of such a development. The paper begins with a description of the evolution of the role of pharmacy technicians and of their status in the workforce today. The next section sets forth a rationale for building a strong pharmacy technician workforce. The paper then turns to three issues that are key to realizing the pharmacy technician's potential: (1) education and training;
(2) accreditation of training institutions and programs; and (3) certification. Issues relating to state regulation of pharmacy technicians are then discussed. The paper concludes with a call to action and summary of major issues to be resolved.

Many of the issues discussed in this report were originally laid out in a white paper developed by the American Pharmaceutical Association (APhA) and the American Society of Health-System Pharmacists (ASHP) and published in 1996. ${ }^{2}$ For this reason, this paper focuses primarily on events that have occurred since that time. Other sources used in the preparation of this paper include Institute of Medicine (IOM) reports, ${ }^{3,4}$ a report to the U.S. Congress on the pharmacy workforce, ${ }^{5}$ and input from professional associations representing pharmacists and technicians as well as from educators, regulators, and consumers.

\section{The Pharmacy Technician: Past to Present}

A pharmacy technician is "an individual working in a pharmacy [setting] who, under the supervision of a licensed pharmacist, assists in pharmacy activities that do not require the professional judgment of a pharmacist." The technician is part of a larger category of "supportive personnel," a term used to describe all non-pharmacist pharmacy personnel. ${ }^{7}$

There have been a number of positive developments affecting pharmacy technicians in the past decade, including national certification, the development of a model curriculum for pharmacy technician training and greater recognition of pharmacy technicians in state pharmacy practice acts. The role of the pharmacy technician has become increasingly well defined in both hospital and community settings. Technicians have gained greater acceptance from pharmacists, and their numbers and responsibilities are expanding. ${ }^{8-11}$ They are starting to play a role in the governance of state pharmacy associations and state boards of pharmacy. Yet more needs to be done. There is still marked diversity in requirements for entry into the pharmacy technician workforce, in the way in which technicians are educated and trained, in the knowledge and skills they bring to the workplace, and in the titles they hold and the functions they perform. ${ }^{12,13}$ The absence of uniform national training standards further complicates the picture. Because of factors such as these, pharmacists and other health professionals, as well as the public at large, have varying degrees of understanding and acceptance of pharmacy technicians and of their role in health care delivery. 
An awareness of developments relevant to pharmacy technical personnel over the last several decades is an essential starting point for any discussion of issues related to pharmacy technicians today and in the future. That information is available in detail elsewhere. ${ }^{14,15}$ A summary of key events of the past halfcentury appears in the following paragraphs.

\section{0s-1990s}

Beginning in the late 1950s, hospital pharmacy and the American Society of Hospital Pharmacists (ASHP) took the lead in advocating utilization of pharmacy technicians (although the term itself had not come into use at the time), in developing technician training programs, and in calling for changes needed to ensure that the role of technicians was appropriately articulated in state law and regulations. ${ }^{16}$ Among the initial objectives was to make a distinction between tasks to be performed by professional and by nonprofessional staff in hospital and community settings. This was largely accomplished by $1969 .{ }^{17,18}$

In the community pharmacy sector, chain pharmacies supported the use of pharmacy technicians and favored on-the-job training. By contrast, the National Association of Retail Druggists (NARD, now the National Community Pharmacist Association [NCPA]), in 1974, stated its opposition to the use of technicians and other "subprofessionals of limited training," out of concern for public safety. ${ }^{14}$

Largely because of its origins, technician practice was initially better defined and standardized in hospitals than in community pharmacies. As the need for technicians in both settings became increasingly apparent, however, many pharmacists and pharmacy educators began to call for collaborative discussions and greater standardization on a number of issues related to pharmacy technicians, and in recent years, progress has been made toward this goal.

\section{The Pharmacy Technician Workforce Today}

Based on Pharmacy Technician Certification Board (PTCB) and Bureau of Labor Statistics (BLS) estimates, there are as many as 250,000 pharmacy technicians in the United States..$^{8,19}$ This is a significant increase over the 1996 estimate of 150,000. ${ }^{2}$ The BLS predicts that pharmacy technician employment will grow by 36 percent or more between 2000 and 2010. ${ }^{8}$ This percentage growth is "much faster than the average for all occupations", but in line with that of a majority of other supportive personnel in the health sector.

Pharmacy technicians work in a wide variety of settings, including community pharmacies (approximately 70\% of the total workforce), hospitals and health systems (approximately 20\%), long-term care facilities, home health care agencies, clinic pharmacies, mail-order pharmacies, pharmaceutical wholesalers, managed care organizations, health insurance companies, and medical computer software companies. ${ }^{8}$ The 2001 Schering Report showed that nine out of ten community pharmacies employ pharmacy technicians. ${ }^{10}$ Recent studies in acute care settings indicate that this figure would be nearly $100 \%$ for the hospital sector. ${ }^{20}$

What functions do technicians perform? Their primary function today, as in decades past, is to assist with the dispensing of prescriptions. A 1999 National Association of Chain Drug Stores (NACDS)/Arthur Andersen study showed that, in a chain pharmacy setting, pharmacy technicians' time was taken up with dispensing (76\%), pharmacy administration (3\%), inventory management (11\%), disease management $(<1 \%)$, and miscellaneous activities, including insurance-related inquiries (10\%). ${ }^{21}$ Surveys by the PTCB have yielded similar results. ${ }^{19,22}$ The nature of dispensing activities may be different in a hospital than in a community pharmacy; in hospitals, technicians may perform additional specialized tasks, such as preparing total parenteral nutrition solutions and intravenous admixtures, preparing medications used in clinical investigations, and participating in nursing unit inspections. ${ }^{22}$

In the past, pharmacists traditionally have been reluctant to delegate even their more routine work to technicians. ${ }^{14}$ The 2001 Schering Report concluded that, in the past five years, pharmacists have become more receptive to pharmacy technicians. And indeed, much has changed in the scope of potential practice activities for pharmacy technicians, as well as pharmacy's perception of the significant role technicians might play. ${ }^{10,23}$ New roles for pharmacy technicians continue to emerge as a result of practice innovation and new technologies., ${ }^{9,11}$ Regardless of their expanded responsibilities, however, many technicians feel they can do more. For example, one study reported that $85 \%$ of technicians employed in chain pharmacies, compared with $58 \%$ of those working in independent pharmacies, felt that their knowledge and skills were being used to the maximum extent. ${ }^{10}$

\section{- Pharmacy Technicians: The Rationale}

Several developments in health care as a whole, and in pharmacy in particular, combine to create an increasing demand for pharmacy technicians; three of significant importance are: (1) the pharmacist workforce shortage, (2) the momentum for pharmaceutical care, and (3) increased concern about safe medication use.

\section{Pharmacist Workforce Shortage}

In 1995, a report by the Pew Health Professions Commission predicted that automation and centralization of services would reduce the need for pharmacists, and that the supply of these professionals would soon exceed demand. ${ }^{24}$ The predicted oversupply has failed to materialize; in fact, there is now a national shortage of pharmacists. A 2000 report of the federal Health Resources and Services Administration (HRSA) states: "While the overall supply of pharmacists has increased in the past decade, there has been an unprecedented demand for pharmacists and pharmaceutical care services, which has not been met by the currently available supply." The workforce shortage is 
affecting all pharmacy sectors. Ongoing studies (by the Pharmacy Manpower Project and other researchers) indicate that the pharmacy manpower shortages will not be solved in the short-term. ${ }^{25}$

For pharmacy practitioners, the results of the workforce shortage are clear: more work must be done with fewer pharmacist staff. Between 1990 and 1999, the number of prescriptions dispensed in ambulatory-care settings increased by $44 \%$, while the number of active pharmacists per 100,000 population increased by only about 5\%.5 Chain pharmacists now fill an average of 86 prescriptions during a normal shift - a 54\% increase since 1993. ${ }^{26}$ NACDS/IMS HEALTH estimate that between 1999 and 2004, the number of prescriptions will increase by $36 \%$ while the number of pharmacists will increase by only $4.5 \% .^{27}$ (Refer Figure 1.)

Faced with greater numbers of prescriptions to dispense, pharmacists have less time to counsel patients. Working conditions and schedules have deteriorated, and job-related stress has risen. ${ }^{10}$ Professional satisfaction has diminished. Perhaps most ominous, fatigue and overwork increase the potential for medication error. ${ }^{5,28}$

Increased use of technicians is one obvious way of reducing workload pressures and freeing pharmacists to spend more time with patients. A white paper issued in 1999 by APhA, NACDS, and NCPA emphasized the need for augmenting the pharmacist's resources through the appropriate use of pharmacy technicians and the enhanced use of technology. ${ }^{29}$

The situation in pharmacy is not unique. A report from the Institute of Medicine concludes that the health care system, as currently structured, does not make the best use of its resources. ${ }^{4}$ Broader use of pharmacy technicians, in itself, will not solve the pharmacist workforce crisis. It would ensure, however, that the profession makes better use of existing resources.

\section{Momentum for Pharmaceutical Care}

More than a decade ago, Hepler and Strand expressed the societal need for "pharmaceutical care." ${ }^{30}$ Since that time, the concept has been refined and its impact on the health care system and on patient care has been documented. Studies have shown that pharmaceutical care can improve patient outcomes, reduce the incidence of negative therapeutic outcomes, and avoid the economic costs resulting from such negative outcomes. ${ }^{31-34}$ Nonetheless, other studies indicate that pharmacists continue to spend much of their time performing routine product-handling functions. ${ }^{20,21}$ Widespread implementation of pharmaceutical care, a goal for the entire profession, has been difficult to achieve thus far.

Technicians are instrumental in the advancement of pharmaceutical care. As Strand suggests, prerequisites to successful implementation of pharmaceutical care include: enthusiastic

pharmacists, pharmacy supportive personnel willing to work in a pharmacy where dispensing is done by technicians rather than pharmacists, and a different mindset-i.e., the pharmacist will no

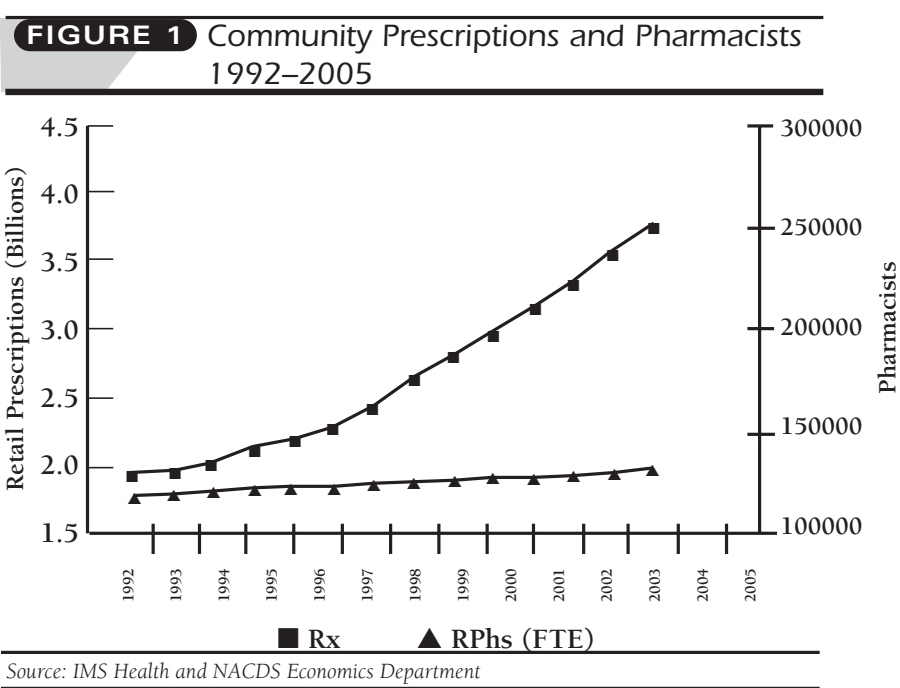

longer be expected to "count and pour" but to "care for patients."35,36

Implementation of pharmaceutical care, in other words, requires a fundamental change in the way pharmacies operate. Pharmacists must turn over routine product-handling functions to competent technicians and technology. This is a difficult shift for many pharmacists to make and pharmacists may need guidance on how to make it. For example, they may need training in how to best use and work with technicians. In recognition of this need, some practice sites have developed successful practice models of pharmacy technicians working with pharmacists to improve patient care. Several of these have been recognized through the PTCB "Innovations in Pharmaceutical Care Award." ${ }^{37}$

\section{Safe Medication Use}

Used inappropriately, medications may cause unnecessary suffering, increased health expenditure, patient harm, or even death. ${ }^{34}$ Ernst and Grizzle estimated the total cost of drug-related morbidity and mortality in the ambulatory care setting in 2000 at more than $\$ 177$ billion - more than the cost of the medications themselves. ${ }^{38}$ They stressed the urgent need for strategies to prevent drug-related morbidity and mortality.

The problems associated with inappropriate medication use have received broad publicity in recent years. For example, To Err Is Human: Building a Safer Health System, published by the Institute of Medicine in 2000, drew attention to medical errors. ${ }^{3}$ It criticized the silence that too often surrounds the issue. Many members of the public were shocked to realize that the system, in which they place so much trust, was far from perfect.

Sometimes pharmacists have been implicated in medication errors. Technicians, too, have not escaped culpability. ${ }^{39-44}$ Several studies, most of which were performed in hospitals, have, however, demonstrated that appropriately trained and supervised pharmacy technicians can have a positive effect on equalizing 
the distributive workload, reducing medication errors, allowing more time for clinical pharmacy practice, and checking other technical personnel. ${ }^{45,46}$ One study showed that pharmacy technicians, when specially trained for the purpose, were as accurate as pharmacists in checking for dispensing errors. ${ }^{47}$ The United States Pharmacopoeia Medication Errors Reporting Program (USP MERP) has noted the contribution that pharmacy technicians can make to medication error prevention in the course of their involvement in inventory management (e.g., identifying problems relating to "look-alike" labeling and packaging). ${ }^{48}$ USP MERP also believes that a "team approach" and "proactive attitudes" by pharmacists and technicians are important elements in reducing medication errors. ${ }^{48}$ The National Coordinating Council for Medication Error Reporting and Prevention advocates that a series of checks be established to assess the accuracy of the dispensing process and that, whenever possible, an independent check by a second individual (not necessarily a pharmacist) should be used. ${ }^{49}$

Reports such as these call for an expanded role for pharmacy technicians in a much-needed, systematic approach to medication error prevention.

\section{Preparing Pharmacy Technicians for Practice} Historical Overview

Originally, all pharmacy technicians received informal, on-thejob training. The majority of pharmacy technicians are probably still trained in this way. ${ }^{8,19,50,51}$ Nevertheless, formal training programs, some of which are provided at the work site, are becoming more widespread. As state regulations, procedures, medications, record-keeping, and insurance requirements have become more complex, there has been a move toward more formal programs. ${ }^{19,52}$ Some employers have found that formal training improves staff retention and job satisfaction. ${ }^{19,53}$ Another advantage of a formal training program is that it can confer a sense of vocational identity. ${ }^{50}$

Formal training programs for pharmacy technicians are not new; they were introduced in the armed forces in the early 1940s, and more structured programs were developed by the military in 1958. In the late 1960s, the Department of Health, Education and Welfare recommended the development of "pharmacist aide" curricula in junior colleges and other educational institutions. ${ }^{54}$ The first formal hospital-based technician training program was initiated around this time. ${ }^{14}$ Training programs proliferated in the 1970s as the profession sought to meet the need for a differentiated pharmacy workforce. ${ }^{55}$ Many of these programs were established in response to requests from hospital pharmacy administrators; there was at that time little interest informally trained technicians in community pharmacies, which continued to train technicians on the job. ${ }^{56}$

In the 1980s, ASHP issued training guidelines that were intended to help hospital pharmacists develop their own training programs. ${ }^{7}$ ASHP recommended minimum entry requirements for trainees and a competency evaluation that included written, oral, and practical components. The guidelines were used not only by hospitals but also by vocational schools and community colleges that wanted to develop certificate and associate degree programs. ${ }^{50}$

Acknowledging the importance of a common body of core knowledge and skills for all pharmacy technicians that would complement site-specific training, the NACDS and NCPA developed a training manual that is arranged into nine instructional sections and a reference section. ${ }^{57}$ Each section has learning objectives, self-assessment questions, and competency assessment for the supervising pharmacist to complete. The manual focuses on the practical, legal, and procedural aspects of dispensing of prescriptions, sterile product compounding, patient interaction, and reimbursement systems. APhA and ASHP also produce technician-training manuals and resource materials for pharmacy technicians. ${ }^{58}$

To date, most programs have referred to the "training", rather than the "education" of pharmacy technicians. Following a review of these "training" programs, further discussion of the need for clarification of the "education" and "training" needs of pharmacy technicians is provided below.

\section{Academic Pharmacy Technician Training Programs}

In 2001, approximately 247 schools or training institutions in 42 states offered a range of credentials, including associate degrees, diplomas, and certificates, to pharmacy technicians. The military also continues to provide formal training programs for pharmacy technicians.

Formal technician training programs differ in many respects, one of which is length. The Accrediting Commission of Career Schools and Colleges of Technology Directory lists 36 "pharmacy" programs. ${ }^{12}$ These programs vary in length from 540 to 2145 contact hours ( 24 to 87 weeks), with a median of 970 hours. ASHP, which accredits technician training programs, requires that programs have a minimum of 600 contact hours and a minimum duration of 15 weeks. ${ }^{59}$ The Pharmacy Technicians Educators Council (PTEC), an association representing pharmacy technician educators, supports the ASHP minimum. ${ }^{60}$

The minimum acceptable length of the program is a matter of debate. Some pharmacy technician educators deplore a move within the education system to get people into the workforce quickly. They feel that the pharmacy profession should make it clear that, while workforce shortages and the needs of the marketplace are an important consideration, rapid-training strategies do not seem appropriate for health care personnel whose activities impact directly on the safe and effective use of medications. ${ }^{52}$ There should be a clear relationship between the nature and intensity of education and/or training, and the scope of practice.Entrance requirements for training programs also vary. Some have expressed concern that a substantial number of trainees may lack the necessary basic skills and aptitude to perform the functions expected of technicians. ${ }^{52}$ The fact that about 
$30 \%$ of a certified pharmacy technician's time is spent performing tasks that require mathematical calculations reinforces the importance of suitably qualified training applicants. ${ }^{22}$ ASHP acknowledged the need for minimum qualifications for training program applicants more than 20 years ago, but the issue continues to be a matter of discussion. ${ }^{7}$

\section{Progress Toward Standardization: The Model Curriculum}

The absence of national training standards and the resultant variations in program content, length, and quality are barriers to the development of a strong technician workforce. The problem is not unique to pharmacy technician training; other occupations in the health care sector also lack national standards. Nonetheless, it would seem ironic that persons in certain other occupations whose services have far less impact on public safety than do those of pharmacy technicians (for example, barbers and cosmetologists) have training programs that, on average, are longer and less diverse than are pharmacy technician programs. ${ }^{61}$ Reflecting a common sentiment on this issue, a 1999 PTEC survey concluded that, "Expansion of the role of pharmacy technicians must be in tandem with standardizing training and establishment of competencies. Increased responsibilities should be commensurate with increased education..."62 Likewise, there was a consensus at the Third PTCB Stakeholders' Forum, held in June 2001, that national standards for pharmacy technician training are needed. ${ }^{63}$

Progress toward standardization has been facilitated by the Model Curriculum for Pharmacy Technician Training. ${ }^{64}$ Having taken the initiative and the leadership role, ASHP collaborated with several other pharmacy associations (APhA, the American Association of Pharmacy Technicians, PTEC, the American Association of Colleges of Pharmacy [first edition only] and NACDS [second edition only]) to develop the model curriculum. The first edition, released in 1996, was based on the findings of the 1992-1994 Scope of Pharmacy Practice Project. ${ }^{65}$ Many of the revisions in the second edition, released in 2001, were based on a 1999 PTCB task analysis, and took into account changes in the scope of activities of today's pharmacy technicians, as well as changes expected to occur over the next five years. ${ }^{22,23}$ Significant changes were made, for example, in sections dealing with the technician's role in enhancing safe medication use and in assisting with immunizations, and with "techcheck-tech", (a system where pharmacy technicians are responsible for checking the work of other technicians, with minimal pharmacist oversight).

The organizations that developed the model curriculum do not expect that every training program will cover every goal and objective of the curriculum; rather, the curriculum should be seen as a "menu" of possible learning outcomes. The model curriculum provides a starting point for identifying core competencies for pharmacy technicians. ${ }^{23}$ It acknowledges the need for a level of understanding of basic therapeutics, anatomy, physiology, and pharmacology. The curriculum does not include recommendations regarding the relative amount of time that should be allotted to each module, but such guidelines are under consideration. ${ }^{66}$

\section{The Future Preparation of Pharmacy Technicians: Education versus Training}

Virtually all the consensus-development meetings and studies that have investigated training requirements for pharmacy technicians have called for the development of standardized training in some form. ${ }^{52,67} \mathrm{APhA}$ and ASHP concur with this position. ${ }^{2,68,69}$

Such a recommendation would best be accompanied by two important caveats. The first is that any national standards for education and training of pharmacy technicians will not eliminate the need for additional, site-specific training that focuses on local policies and procedures..$^{52,63}$ Second, a standards-based education or training can, conceivably, be delivered successfully in a variety of different settings.

However, is it clear what exactly is meant when the terms "education" and "training" are applied to pharmacy technicians? They have tended in the past to be used somewhat interchangeably. There is, however, a distinction that needs to be made, and a balance between the two that needs to be reached, to ensure that pharmacy technicians are adequately and appropriately prepared to perform, in a safe and efficient manner, the functions and responsibilities that are assigned to them - both now and in the future. As has already been noted in this paper, the roles and responsibilities of pharmacy technicians have evolved and expanded in recent years. While, in the main, pharmacy technicians perform routine tasks that do not require the professional judgment of a pharmacist, state pharmacy practice acts now recognize that pharmacy technicians are being assigned new and different functions in the practice setting, some of which may require a level of judgment and/or product knowledge and understanding.

Training involves learning through specialized instruction, repetition and practice of a task, or series of tasks, until proficiency is achieved. Education, on the other hand, involves a deeper understanding of a subject, based on explanation and reasoning, through systematic instruction and teaching. Conceivably a person may be proficient in performing a task, without knowing why they are doing it, what its importance is, or the logic behind the steps being performed. While education (as described above) may involve a training component, both are vital to the learning (or preparation) of the technician. Barrow and Milburn give a useful treatise on this subject. ${ }^{70}$ The education and training of pharmacy technicians (and other supportive personnel) must be commensurate with the roles they are performing. To ensure quality, both the education and training components should be standards-based.

Accreditation of Pharmacy Technician Education and Training

The Council on Credentialing in Pharmacy (CCP) defines 
accreditation as "the process by which a private association, organization, or government agency, after initial and periodic evaluations, grants recognition to an organization that has met certain established criteria." ${ }^{71}$ Accreditation is an integral aspect of ensuring a quality educational experience.

For pharmacy technician education and training, there are two types of accreditation - programmatic (also referred to as "specialized") and institutional. Programmatic accreditation focuses specifically on an individual program, whereas institutional accreditation evaluates theeducational institution as a whole, with less specific attention being paid to the standards of individual programs offered by the institution. Institutional accreditors operate either on a regional or national basis; the latter usually having a more focused area of interest. A system of dual accreditation, where institutional accreditation is carried out by regional accrediting bodies and programmatic accreditation is carried out by the American Council on Pharmaceutical Education (ACPE), has worked well for schools and colleges of pharmacy since the 1930s.

Based on information obtained from published directories, it is estimated that only $43 \%$ of the 247 schools and training institutions referred to earlier are accredited by bodies specializing in technical, allied health and para-professional education, 36\% have their programs accredited by ASHP and 12\% are accredited by both ASHP and one, or more, of the institutional accrediting bodies specializing in technical, allied health and para-professional education.

\section{Institutional Accreditation}

For institutions offering pharmacy technician training, national institutional accreditation is carried out by at least four agencies the Accrediting Commission of Career Schools and Colleges of Technology (ACCSCT), the Accrediting Bureau of Health Education Schools (ABHES), the Council on Occupational Education (COE) and the Accrediting Council for Independent Colleges and Schools (ACICS). All of these agencies are recognized by the U.S. Department of Education. None have a formal national affiliation with the profession of pharmacy.

Because there are no nationally adopted standards for pharmacy technician training, it is difficult for institutional accrediting bodies to set detailed program requirements. ACCSCT standards require programs to have an Advisory Committee, the majority of whose members represent employers in the field of training. ${ }^{72}$ ABHES has a suggested curriculum outline for pharmacy technician programs. In an effort to improve the quality of their programs, COE and ABHES plan to switch from institutional to program accreditation. ${ }^{73}$ Of some concern is the fact that such accreditation systems (for pharmacy technician training programs) would be outside the pharmacy profession, and would not be based on standards recognized nationally by the profession.

\section{Program Accreditation}

Program accreditation for technician training is offered by the
American Society of Health-System Pharmacists. ASHP accreditation of technician training programs began in 1982 at the request of hospital pharmacists. Many hospital-based technician training programs were already using ASHP guidelines and standards, but they expressed a need for a more formal method of oversight to ensure the quality of training. ASHP already accredited pharmacy residency programs, and moving into technician accreditation seemed a logical step.

Initially, nearly all ASHP-accredited programs were hospital based. This is no longer the case; of the nearly 90 techniciantraining programs currently accredited by ASHP, only three are hospital based. Over $90 \%$ of programs are located at vocational, technical, or community colleges. ${ }^{74}$

The objectives, standards, and regulations of the accreditation program, as well as a directory of accredited programs, are available on the ASHP Web site..$^{5,74-76}$ The accreditation standards are geared toward preparing technicians for all practice settings and, therefore, require that pharmacy technicians be trained in a wide variety of practice environments, and that they complete laboratory exercises before beginning their experiential training.

While accreditation is voluntary for both pharmacy degree programs and technician-training programs, an important distinction exists. State boards of pharmacy and NAPLEX ${ }^{77}$ have recognized ACPE accreditation as an eligibility for the pharmacist licensing examination. Completion of an accredited program is not usually a prerequisite for employment, registration, or certification as a pharmacy technician. However, accreditation does bring a number of benefits. For the program, the benefits include enhanced recruitment potential for trainees, improved marketing, and the opportunity for peer review and quality improvement. For employers, completion of an accredited program may be an indication of the level of competence of a technician. Most importantly, accreditation provides all stakeholders with an objective, external, and independent evaluation of the quality of the education or training experience. Employers have a strong interest in the quality of training of their employees, not least of which is in terms of potential liability issues were they also to be the provider of the training. It would, therefore, also appear to be in the best interests of employers for the onus of quality assurance to rest with an independent party.

\section{A New Role for ACPE?}

ASHP recognizes that the education, training and utilization of pharmacy technicians now has broader professional implications than it did when it introduced its accreditation program nearly 20 years ago. For this reason, ASHP has asked the American Council on Pharmaceutical Education (ACPE) to explore assuming responsibility for this function. Many people now believe that accreditation is best carried out by an independent agency that has no direct or indirect interest in the provision of training or in the activities of the graduates of the training program. ${ }^{78}$ 
Involving ACPE might have an additional advantage, should a decision be made to develop national training standards. ACPE, which has broad experience spearheading collaborative efforts to develop educational standards for pharmaceutical education, could be an appropriate organization to lead the process of developing uniform national standards for technician education and training. Responses to a 2000 ACPE survey indicate strong support for an ACPE role in this area. ${ }^{79}$

\section{Certification of Pharmacy Technicians}

Certification is the process by which a non-governmental agency or association grants recognition to an individual who has met certain predetermined qualifications specified by that agency or association. ${ }^{2}$ For pharmacy, the Pharmacy Technician Certification Board, created in 1995, has been one of the most positive developments of the past halfdecade. "Certified Pharmacy Technician," or CPhT, is the only national credential available to pharmacy technicians. A credential is documented evidence of an individual's or program's qualifications or characteristics. Credentials may include diplomas, licenses, certificates, and certifications. ${ }^{71}$ The Council on Credentialing in Pharmacy (CCP) was established in 1999. The development and application of credentialing standards for the pharmacy profession are integral components of CCP's vision and mission statements. PTCB was one of CCP's founding organizations. For a pharmacy technician, certification is an indication of the mastery of a specific core of knowledge. ${ }^{2}$ Certification is mainly voluntary, although some state boards of pharmacy have moved to requiring certification (see section entitled "Regulation of Pharmacy Technicians").

The PTCB examination is based on a task analysis that defined the work of pharmacy technicians nationwide: $64 \%$ of the exam is based on knowledge required to assist the pharmacist in serving patients; $25 \%$ on medication distribution and inventory control systems; and $11 \%$ on the administration and management of pharmacy practice. ${ }^{22}$ By the end of 2001, more than 100,000 technicians had been certified under this program. ${ }^{37} \mathrm{CPhTs}$ must renew certification every two years and complete at least 20 hours of pharmacy-related continuing education (including an hour of pharmacy law) over that period.

For many technicians, achieving PTCB certification is an important part of their professional development. ${ }^{19}$ Many pharmacy chains have recognized the value of certification, and provide assistance and incentives to staff to achieve certification, including reimbursement of costs, advancement to a higher grade, and a salary increase. ${ }^{19}$ Studies have revealed that certified technicians remain in practice longer than non-certified technicians do. Staff turnover of both pharmacists and technicians has gone down in pharmacies employing certified technicians. Improved staff morale, higher productivity, reduced errors, and higher levels of customer satisfaction have also been noted. ${ }^{80,81}$ Additional benefits for employers include improved risk management, reduced technician training times and lower training costs. ${ }^{82}$ Some pharmacists feel more confident delegating dispensing activities to certified technicians than to technicians who are not certified. ${ }^{10,22}$

PTCB recognizes the need to reassess and modify its policies and procedures, as well as the examination, in response to the changing needs of practice and of the profession, as well as trends in the marketplace. To make such assessments, PTCB engages in research and seeks input from its stakeholders. PTCB also reviews its eligibility criteria for candidates who wish to sit for the certification examination. Under consideration are specialty certification assessments in areas such as preparation of intravenous admixtures and third party payment systems.

\section{Regulation of Pharmacy Technicians} Introduction

For many years, most state boards of pharmacy, often reflecting the attitudes of pharmacists, opposed recognizing technicians and expanding the scope of their activities. ${ }^{52,83}$ As pharmacists' roles changed and use of supportive personnel expanded, these attitudes began to shift. Over thepast five years, a majority of states have revised their pharmacy practice acts in areas related to technicians. Today, Ohio is the only state that does not formally address pharmacy technicians in state statutes or regulations.

The National Association of Boards of Pharmacy (NABP) regularly surveys state pharmacy practice acts. The results of these surveys are bellwethers of change at the state level; collectively, they reveal trends. The most recent survey was done in 2001. ${ }^{13}$ To highlight changes that have taken place since the publication of the 1996 White Paper, the results of NABP's $1996 / 1997^{84}$ and 2001/2002 surveys are compared. The NABP also appoints task forces to study and make recommendations on major issues. The deliberations of these task forces have resulted in, among other things, a call for formal recognition of pharmacy technicians, simplified state registration procedures, site-specific training, a national technician competency exam, and a disciplinary clearinghouse. Key developments in regulation, as evidenced in the NABP surveys, and in recent NABP task force recommendations and actions, are summarized in the following paragraphs.

\section{Changes in State Regulations: 1996-2001}

Terminology. In the 1996/1997 NABP survey, at least 11 terms were used to describe pharmacy supportive personnel. At that time, 24 states used the term "pharmacy technician." By 2001, 38 states had adopted this designation.

Technician Registration. In its "model act", designed to provide boards of pharmacy with model language that may be used when developing state laws or board rules, NAPB advocates that pharmacists be licensed and that pharmacy technicians be registered. ${ }^{85}$ "Registration" is defined as the process of making a list or being included on a list. It carries no indication or guarantee of the registrant's knowledge or skills. "Licensure" is the process by which an agency of government grants permission to 
an individual to engage in a given occupation upon finding that the applicant has attained the minimal degree of competency necessary to ensure that the public health, safety and welfare will be reasonably well protected. ${ }^{2}$ Like NABP, ASHP and APhA support registration and oppose licensure of pharmacy technicians. APhA and ASHP believe that licensed pharmacists must retain responsibility and accountability for the quality of service in a pharmacy. ${ }^{68,69,86}$

By 2001, 24 states required registration and 5 required "licensure" of pharmacy technicians, in line with the NABP recommendations. Although the term "license" is used in these regulations, in some cases the process would appear to more closely resemble "registration", in terms of the definitions used in this paper. The increase in the number of states (up from 14 in 1996) that now require either registration or licensure of pharmacy technicians, is noteworthy.

Pharmacist: Technician Ratios. Since 1996, at least 25 states have liberalized their pharmacist: technician ratios (from a norm of $1: 1$ or $1: 2$, to a norm of $1: 2$ or $1: 3)$. Some states further relaxed ratios in sites where certified pharmacy technicians are employed. In their 1996 white paper, APhA and ASHP called for a reassessment of mandated arbitrary pharmacist: technician ratios. ${ }^{2}$ This stance reflects the organizations' conviction that the pharmacist should be responsible andaccountable for pharmacy technicians under their charge. ${ }^{68,69}$ NACDS believes that each practice setting should be allowed to determine its own optimal ratio. ${ }^{87}$ Following the recommendation of a 1999 Task Force on Standardization of Technicians' Roles and Competencies, ${ }^{88}$ NABP encouraged states to modify or eliminate ratios in pharmacy settings with quality assurance programs in place.

Standard Training Requirements. Between 1996 and 2001, the number of states that had incorporated training requirements into their regulations rose by 34\% (from 19 to 26). Training requirements had been recommended in 1996 by an NABP task force.

The training requirements that state boards have put in place are in some cases minimal. Many states require nothing more than a training manual; there are no detailed minimum requirements. Some states, on the other hand, have enacted competency-based regulations, or well-defined standards for training program assessment. ${ }^{89}$ Some states require continuing education for renewal of registration or licensure; others are considering such a requirement.

Technician Certification. A small number of states have made certification a requirement for registration or licensure..$^{90}$ Texas was the first to introduce the requirement in 1996. The law was implemented in January 2001; a provision exists, however, for certain technicians to be exempted. ${ }^{91}$ In Utah, the licensing authority has defined compliance with minimum training standards, as well as certification and the passing of a law examination, as requirements for licensure. ${ }^{92}$ Some states have altered pharmacist:technician ratios, responsibilities, supervision, or other requirements on the basis of a technician's certification status. ${ }^{93}$

Levels of Personnel and Scope of Practice. Based on findings of its 1999 task force (referred to above), NABP has recognized two levels of supportive personnel - "pharmacy technician" and "certified pharmacy technician", and specified the scope of practice that would be allowed for technicians working under the supervision of a pharmacist. ${ }^{94-96}$ The task force had recommended a third, and higher, level of supportive personnel - the "pharmacist assistant" — but the NABP did not adopt this recommendation. APhA and ASHP likewise oppose the creation of this category of supportive personnel. ${ }^{68,69}$

Many of the changes in state regulations are reflected in the functions that technicians perform. For example, the number of states allowing a pharmacy technician to "Call physician for refill authorization" increased by $41 \%$ (from 25 to 36) in a hospital/institutional setting and by $47 \%$ (from 24 to 36 ) in a community setting between 1996 and 2001. Few states have traditionally allowed pharmacy technicians in any work setting to accept called-in [new] prescriptions from a physician's office, and there was little change in this area in the last five years. There was likewise little change in the dispensing-related activities that pharmacy technicians perform; however, the percentage of states allowing these activities was already high (generally $>85 \%$ in 1996). The only dispensing-related activity to show a more than $15 \%$ increase (in the number of states that allow it) in the past five years is "Reconstitution of oral liquids," which increased by $22 \%$ (from 41 to 51 ) in hospitals and by $23 \%$ (from 40 to 50) in community settings. In the hospital/institutional setting, the number of states allowing technicians to "Compoundmedications for dispensing" increased by 33\% (from 34 to 46); the number increased by 24\% (from 34 to 43) in the community setting.

Competency Assessment. In May 2000, NABP resolved that it would: (1) develop a national program to assess the competencies necessary for technicians to safely assist in the practice of pharmacy, (2) review existing technician certification programs to determine whether the development of its competence assessment program should be a cooperative effort with other groups, and (3) urge state boards to use this program as one criterion in determining the eligibility of technicians to assist in the practice of pharmacy. ${ }^{97}$ NABP has now joined PTCB on the national certification program for pharmacy technicians, and will work with state boards of pharmacy to encourage acceptance of the PTCB certification program as a recognized assessment tool for pharmacy technicians. ${ }^{98}$ The use of the PTCB certification program will also be incorporated into NABP's Model State Pharmacy Act and Model Rules.

\section{The Need for Regulation}

The difficulties stemming from lack of regulatory oversight over pharmacy technicians go further than one might initially foresee. For example, if state regulations do not recognize a class of personnel (through registration or licensure), it is difficult to 
discipline such personnel in the event of misconduct. Several state boards have reported that the absence of such regulation is creating problems. ${ }^{99}$ For example, in the absence of adequate controls, pharmacy technicians, who have committed an act of misconduct, such as drug diversion, can move from site to site, or state to state, without being traced or being held accountable. NABP, and many state executives and pharmacists have called for better systems of control and measures to track disciplinary actions. By 2000, at least 25 states had incorporated disciplinary procedures for technicians in their regulations. ${ }^{97}$

Among the regulatory issues that remain in flux, none is more important than defining the roles and responsibilities of supportive personnel and the titles they are assigned. Pharmacy supportive personnel perform a wide array of services. Some state regulations recognize this and have differentiated levels of supportive personnel; some states have specific requirements for technicians-in-training. Multiple levels of pharmacy supportive personnel may continue to be required in the future, and the levels may vary among and within practice settings. The profession needs to determine what these levels should be and to define the role and function, competencies, education, training, and level of supervision appropriate for each.

\section{Time for Action}

Pharmacy faces a serious workforce shortage at a time when the public and health care providers alike are looking to pharmacists to assume expanded responsibility for better medication use. Better use of human resources is essential. When pharmacists limit their direct involvement in the technical aspects of dispensing, delegate this responsibility to pharmacy technicians working under their supervision, and increase the use of automated dispensing technology, they can fully concentrate on the services for which they are uniquely educated and trained. Only then will Dr. Tice's vision of the future become reality.

The utilization, education, training, and regulation of pharmacy technicians have changed dramatically in the past five years. National certification has played a particularly important role in these changes. Nonetheless, many challenges remain. Because these challenges are interrelated, resolving them requires a coordinated approach. The profession needs a shared vision for pharmacy technicians and other supportive personnel. This vision will provide the framework within which further necessary change can take place. Beginning with that much-needed vision, the major issues to be discussed and resolved might be expressed as follows:

\section{Vision}

- Define a vision for pharmacy technicians as an integral part of the vision and mission of the profession of pharmacy.

- Develop goals, objectives, and strategies to realize this vision, including determining who will lead the process and the specific roles, present and future, of all parties;

- Communicate the vision and goals to all stakeholders, including policy makers and the public.

\section{Roles, Responsibilities, and Competencies}

- Define the different levels of pharmacy supportive personnel and the responsibilities or functions appropriate for individuals at each level.

- Determine the competencies required for high-level performance at each level.

\section{Education and Training}

- Establish standards (including eligibility criteria) for the education and training of each level of pharmacy supportive personnel.

- Establish requirements for maintenance of competence, where applicable, and create the systems to achieve this.

- Consider the cost implications of any new training model, and devise appropriate strategies to address cost concerns.

\section{Credentialing and Accreditation}

- Develop or enhance appropriate credentials, in collaboration with PTCB and the Council on Credentialing in Pharmacy (CCP), to reflect what is happening and required in practice.

- Determine what the most appropriate systems of accreditation for education and training programs for pharmacy technicians are, and who should lead this process on behalf of the profession.

\section{Regulation}

- Determine the appropriate regulatory framework under which pharmacy technicians can optimally contribute to the achievement of pharmacy's mission.

- Work to bring about further changes in state pharmacy practice acts and regulations in order to achieve the desired regulatory framework.

- Work to bring about the development and adoption of standardized definitions and terminology for pharmacy supportive personnel.

\section{Conclusion}

Change does not come easily, and it is seldom embraced by everyone. As Kenneth Shine, M.D., put it, when discussing the need for change in the health system: "The issue...will be whether these needed changes occur only begrudgingly as a reaction to external forces, or whether they occur proactively as a result of professional leadership."100 The profession of pharmacy is changing in response to internal as well as external influences. Both pharmacists and pharmacy technicians are, therefore, part of an evolving partnership. Pharmacy must respond to the changes that are already taking place and be sufficiently creative and flexible to anticipate and accommodate future developments. The need to address the issues surrounding pharmacy technicians in a timely manner cannot be overemphasized. Proper preparation of pharmacy technicians 
to work with pharmacists is important in the promotion of public health and better use of medication. The Council on Credentialing in Pharmacy, on behalf of its member organizations, offers this paper to provide a stimulus for profession-wide action that can no longer wait.

\section{REFERENCES AND EXPLANATORY NOTES:}

1. Sonnedecker G. Kremers and Urdang's History of Pharmacy: 4th ed. The American Institute of the History of Pharmacy. 1976:241

2. American Society of Health-System Pharmacists. White paper on pharmacy technicians. Am J Health-Syst Pharm. 1996; 53:1991-4.

http://www.ashp.org/bestpractices/PharmMgmt/HR/Endorsed/248-251 Human Resources.pdf Accessed 2002 Apr 3

3. Kohn LT, Corrigan JM, Donaldson MS, ed. Committee on Quality of Health Care in America, Institute of Medicine. To err is human: building a safer health system. Washington, D.C.: National Academy Press; 1999

4. Committee on Quality of Health Care in America, Institute of Medicine. Crossing the quality chasm: a new health system for the 21st century. Washington, D.C.: National Academy Press; 2001.

5. Bureau of Health Professions. Report to Congress: The pharmacist workforce: a study of the supply and demand for pharmacists. Washington, D.C. U.S. Department of Health and Human Services, 2000.

6. Pharmacy Technician Certification Board. 1995 candidate handbook national pharmacy technician certification examination. Washington, DC: Pharmacy Technician Certification Board; 1995:15.

7. American Society of Hospital Pharmacists. ASHP technical assistance bulletin on outcome competencies and training guidelines for institutional pharmacy technician training programs. Am J Hosp Pharm. 1982; 39:317-20.

8. Bureau of Labor Statistics, U.S. Department of Labor: Occupational Outlook Handbook. http://www.bls.gov/oco/ocos252.htm Accessed 2002 April 3.

9. Ervin KCA, Skledar S, Hess MM et al. Data analyst technician: an innovative role for the pharmacy technician. Am J Health-Syst Pharm. 2001; 58:1815-8.

10. Schering Laboratories. Pharmacists, technicians, and technology: serving the patient. Schering Report XXIII. Kenilworth, NJ: 2001.

11. Traynor K. Technician careers continue to evolve. Newsletter of the Maryland Society of Health-System Pharmacists. 2001; 24(4):1,4.

12. The Accrediting Commission of Career Schools and Colleges of Technology Directory. Available from Internet. http://www.accsct.org/resource/ resource_mainframe.html Accessed 2002 April 3

13. National Association of Boards of Pharmacy. 2001-2002 Survey of Pharmacy Law. Park Ridge, IL: 2001:34-44. Used with permission.

14. American Society of Hospital Pharmacists. Final report of the ASHP task force on technical personnel in pharmacy. Am J Hosp Pharm. 1989; 46:1420-9.

15. American Society of Health-System Pharmacists Website. Chronology of ASHP activities for pharmacy technicians. http://www.ashp.org/technicians/ chronology.html Accessed 2002 March 27.

16. Zellmer WA. Priorities for hospital pharmacy in the 1980s. Am J Hosp Pharm. 1980; 37:481. Editorial.

17. American Society of Hospital Pharmacists. Workshop on sub-professional personnel in hospital pharmacy, 1969 Jan. Am J Hosp Pharm. 1989; 46:1420-9.

18. American Pharmaceutical Association. Task force report on roles of the practitioner of pharmacy and the sub-professional in pharmacy, Aug 1969. Am J Hosp Pharm. 1989; 46:1420-9.

19. Pharmacy Technician Certification Board: published and unpublished research, surveys and employer consultations.
20. Ringold DJ, Santell JP, Schneider PJ. ASHP national survey of pharmacy settings: dispensing and administration. Am J Health-Syst Pharm. 2000; 57:1759-1775. http://www.ashp.org/public/pubs/ajhpopen/10a-rringold.pdf Accessed 2002 March 27

21. Arthur Anderson LLP. Pharmacy activity cost and productivity study. 1999. (Technician deployment figures rounded.) http://www.nacds.org/userassets/PDF_files/arthur_andersen.PDF Accessed 2002 March 27.

22. Muenzen PM, Greenberg S, Murer MM. PTCB task analysis identifies role of certified pharmacy technicians in pharmaceutical care. J Am Pharm Assoc. $1999 ; 39: 857-64$

23. American Society of Health-System Pharmacists. Model curriculum for pharmacy technician training. 2nd ed. Bethesda, MD: 2001. Preface. http://www.ashp.org/technicians/model_curriculum/preface_second.pdf Accessed 2002 March 27.

24. Pew Health Professions Commission. Critical challenges: revitalizing the health professions for the twenty-first century. San Francisco, CA. The Center for Health Professions, University of California, 1995

25. Gershon SK., Cultice JM, Knapp KK. How many pharmacists are in our future? The Bureau of Health Professions projects supply to 2020. J Am Pharm Assoc. 2000; 40:757-64

26. National Association of Chain Drug Stores Website Consumer Information Page. "Pharmacy: playing a growing role in America's health care." http://www.nacds.org/ Accessed 2001 Nov 29.

27. IMS HEALTH and NACDS Economics Department. Used with permission.

28. Kelly WN. Pharmacy contributions to adverse medication events. Conference report: Understanding and preventing drug misadventures. http://www.ashp.com/public/proad/mederror/pkel.html Assessed 2002 March 27. http://www.mederrors.com/pdf/bibliography.pdf Accessed 2002 March 27.

29. National Association of Chain Drug Stores, American Pharmaceutical Association, National Community Pharmacists Association. White paper Implementing effective change in meeting the demands of community pharmacy practice in the United States; 1999.

30. Hepler CD, Strand LM. Opportunities and responsibilities in pharmaceutical care. Am J Hosp Pharm. 1990; 47:533-43.

31. American Pharmaceutical Association Foundation Website: Project ImPACT page. http://www.aphafoundation.org/Project_Impact/Impact.htm Accessed 2002 March 28

32. Johnson JA, Bootman JL. Drug-related morbidity and mortality: a cost-ofillness model. Arch Intern Med. 1995; 155:1949-56.

33. Johnson JA, Bootman JL. Drug-related morbidity and mortality and the economic impact of pharmaceutical care. Am J Health-Syst Pharm. 1997; 54:554-8.

34. Bootman JL, Harrison DL, Cox E. The health care cost of drug-related morbidity and mortality in nursing facilities. Arch Intern Med. 1997; 157:2089-96

35. Strand LM. Building a practice in pharmaceutical care: Hoechst Marion Roussell Lecture. PJ. 1998; 260:874-6

36. Strand LM. Pharmaceutical care seminar: Liverpool John Moores University. PJ. 1998; 260:877-8

37. Pharmacy Technician Certification Board Website. http://www.ptcb.org/ Accessed 2002 March 28

38. Ernst FR, Grizzle AJ. Drug-related morbidity and mortality: updating the cost-of-illness model. J Am Pharm Assoc. 2001; 41:192-9.

39. Lease D. Can you trust your pharmacist? Herald-Tribune; Editorial Sarasota, FL; 2000 Jul 20. http://speakout.com/activism/opinions/2850-1.html Accessed 2002 Mar 28

40. Schuman D. When pharmacies make mistakes. The News-Sentinel; Story. Fort Wayne, IN; 1999 Nov 15. http://www.news-sentinel.com Archives accessed 2002 March 28

41. Levine J. Assistants' role in the spotlight: study finds mistakes by pharmacy technicians. WebMD Website; 2000 Feb 23. http://my.webmd.com/content/article/1728.55198 Accessed 2002 March 28. 
42. Stolberg SG. Death by prescription: the boom in medications brings rise in fatal risks. The New York Times; 1999 Jun 3.

http://www.nytimes.com/library/national/science/060399sci-prescriptions.html Accessed 2002 March 28.

43. Hendren J. Pharmacy technicians dispense drugs: prescriptions often filled by lower-paid technicians. Cape Cod Times; 2000 Mar 7. Port Richey, FL. Reprinted with permission: J Pharm Technol. 2000; 16:112-4 http://www.capecodonline.com/cctimes/archives/2000/mar/7/prescriptionsoften7.htm Accessed 2002 March 28.

44. Dooley K. 'Support personnel' handle pills: few standards regulate important job. Lexington Herald-Leader; 2001 Oct 22. Lexington, KY.

45. Kalman MK, Witkowski DE, Ogawa GS. Increasing pharmacy productivity by expanding the role of pharmacy technicians. Am J Hosp Pharm. 1992; 49:84-9.

46. Woller TW, Stuart J, Vrabel R et al. Checking of unit dose cassettes by pharmacy technicians at three Minnesota hospitals: pilot study. Am J Hosp Pharm. 1991; 48:1952-6.

47. Ness JE, Sullivan SD, Stergachis A. Accuracy of technicians and pharmacists in identifying dispensing errors. Am J Hosp Pharm. 1994;

51:354-7.

48. Cowley E, Baker KR. Report based on presentations. Liability for errors in expanded pharmacy practice: issues for technicians and pharmacists. J Am Pharm Assoc. 2000; 40:S56-7.

49. National Coordinating Council for Medication Error Reporting and Prevention. Recommendations for avoiding error-prone aspects of dispensing medications. Rockville, MD: 1999 Mar 19.

http://www.nccmerp.org/rec_990319.htm Accessed 2002 April 1.

50. Ray MD. Training hospital pharmacy technicians. Am J Hosp Pharm. 1984; 41:2595. Editorial.

51. Reeder CE, Dickson M, Kozma CM et al. ASHP national survey of pharmacy practice in acute care settings - 1996. Am J Health-Syst Pharm. 1997; 54:653-69. http://www.ashp.org/public/proad/mederror/3b-rsanabs.html Abstract accessed 2002 Apr 4.

52. Keresztes J, Palmer M, Lang SM et al, ed. National pharmacy technician conference: looking toward the future. J Pharm Technol. 2001; 17:S1S26.

53. Sanford ME, Faccinetti NJ, Broadhead RS. Observational study of job satisfaction in hospital pharmacy technicians. Am J Hosp Pharm. 1984; 41:2599- 606 .

54. Department of Health, Education and Welfare. Task force on prescription drugs; 1968 Aug. Am J Hosp Pharm. 1989; 46:1420-9.

55. American Society of Hospital Pharmacists. ASHP long-range position statement on pharmacy manpower needs and residency training. Am J

Hosp Pharm. 1980; 37:1220.

56. Eichelberger BM. College based technician training programs: producing without planning? Am J Hosp Pharm. 1979; 36:992-3.

57. Schafermeyer KW, Hobson EH, ed. The community retail pharmacy technician training manual. 3rd ed. National Association of Chain Drug Stores and National Community Pharmacists Association; Alexandria, VA: 1999.

58. American Pharmaceutical Association. Pharmacy technician certification: quick-study guide. 2nd ed. Washington, DC: 2000: American Pharmaceutical Association. Complete review for the pharmacy technician. Washington, DC: 2001: American Pharmaceutical Association. Complete math review for the pharmacy technician. Washington, DC: 2001: American Society of HealthSystem Pharmacists. Manual for pharmacy technicians. 2nd ed. Bethesda MD: 1998: American Society of Health-System Pharmacists. Pharmacy technician certification review and practice exam. Bethesda, MD: 1998.

59. American Society of Health-System Pharmacists Commission on Credentialing. Accreditation standard for pharmacy technician training programs. Bethesda, MD: 1997. http://www.ashp.org/technicians/techstnd.pdf Accessed 2002 April 1.

60. The Pharmacy Technicians Educators Council: Policy statements (Unpublished; used with permission)
61. Rouse MJ. Analysis of 36 "pharmacy" [technician] programs, 36 "barbering and styling" programs and 34 "cosmetology and styling" programs listed in the ACCSCT Directory;12 2001Nov. (Unpublished.)

62. Moscou K. Pharmacy technician educators' attitudes toward education and training requirements for pharmacy technicians. J Pharm Technol. 2000; 16: 133-7.

63. Pharmacy Technician Certification Board. Third Annual Stakeholder Forum; Leesburg, VA: 2001 Jun 13-14. (Proceedings not yet published.)

64. American Society of Health-System Pharmacists. The model curriculum for pharmacy technician training. 1st ed.: 1996; 2nd ed.: 2001. http://www.ashp.org/technicians/model_curriculum/ Accessed 2002 April 1.

65. Summary of the final report of the Scope of Pharmacy Practice Project. Am J Hosp Pharm. 1994; 51:2179-82

66. Nimmo CM, Model Curriculum Committee Leader. Personal communication with author; 2001 Oct.

67. American Society of Hospital Pharmacists Research and Education Foundation. Technical personnel in pharmacy: directions for the profession in society; proceedings of an invitational conference conducted by the University of Maryland Center on Drugs and Public Policy; Baltimore, MD: 1988 Oct 29 - Nov 1. Am J Hosp Pharm. 1989; 46:491-557.

68. The American Pharmaceutical Association: Policy statements submitted by APhA and used with permission.

69. The American Society of Health-System Pharmacists House of Delegates: Professional policies adopted at the 54th annual session; 2002 Jun 2 and 4. Am J Health-Syst Pharm. 2002; (awaiting reference)

70. Barrow W, Milburn G. A critical dictionary of educational concepts. 2nd ed. New York, NY: Teachers College Press; 1970.

71. Council on Credentialing in Pharmacy. Guiding principles for pharmacy credentialing activities. Washington, DC: 2001 Nov 1. Used with permission. http://www.pharmacycredentialing.org/ Accessed 2002 Apr 1.

72. The Accrediting Commission of Career Schools and Colleges of Technology (ACCSCT) Website: http://www.accsct.org/getting/get_mainframe.html Accessed 2002 April 1.

73. Eaton CJ, Associate Executive Director, Accrediting Bureau of Health Education Schools; Puckett G, Associate Executive Director, Council on Occupational Education. Personal communications with author; 2001 Nov.

74. American Society of Health-System Pharmacists. ASHP-Accredited Pharmacy Technician Training Program Directory http://www.ashp.org/directories/technician/index.cfm Accessed 2002 April 1.

75. American Society of Health-System Pharmacists Commission on Credentialing. ASHP regulations on accreditation of pharmacy technician training programs. Bethesda, MD: 1997.

http://www.ashp.org/technicians/techregs.pdf Accessed 2002 April 1.

76. American Society of Health-System Pharmacists Website: Pharmacy Technicians Page http://www.ashp.org/technicians/index.html Accessed 2002 April 1.

77. NAPLEX ® (North American Pharmacist Licensure Examination ${ }^{\mathrm{TM}}$ ). Registered trademark of the National Association of Boards of Pharmacy, Park Ridge, IL.

78. Association of Specialized and Professional Accreditors (ASPA). Member code of good practice. Chicago, IL: 1995. http://www.aspausa.org/ Accessed 2002 April 1.

79. American Council on Pharmaceutical Education. ACPE Strategic Plan Survey; 2000. Question 58: "ACPE should convene an open conference to discuss the need for educational standards for pharmacy technicians." (>80\% favorable response, using 8-point Likert scale.) (Unpublished.)

80. Burkhart A. Pharmacy's challenging environment: technicians as part of the solution. Presentation at APhA Annual Meeting. San Francisco, CA; 2001 Mar 19.

81. Nouri L. The utilization of certified pharmacy technicians with automation and technology. Paper presented at APhA Annual Meeting. Washington, DC; 2000 Mar. 
82. Murer MM. Innovations for enhancing patient safety and new roles for certified pharmacy technicians. Paper presented at the 36th Annual ASHP Midyear Clinical Meeting. New Orleans, Louisiana. 2001 Dec 4.

83. American Pharmaceutical Association House of Delegates, 1971. Am J Hosp Pharm. 1989; 46:1420-9.

84. National Association of Boards of Pharmacy. 1996-1997 Survey of Pharmacy Law. Park Ridge, IL. 1997:32-40.

85. National Association of Boards of Pharmacy. The Model State Pharmacy Act and Model Rules. Park Ridge, IL: 2001

86. Gans JA, Manasse HR. White paper on pharmacy technicians.

Memorandum to executive directors of state boards of pharmacy, state pharmacists associations and state health-system pharmacists societies. 1997 Oct 20.

87. The National Association of Chain Drug Stores Issue Brief; 2001 Oct. (Unpublished) Used with permission.

88. National Association of Boards of Pharmacy. Report of the Task Force on Standardization of Technicians' Roles and Competencies. Park Ridge, IL: 1999. (Unpublished.) Used with permission.

89. California, Kansas, Indiana, Washington.

90. Louisiana, New Mexico (required by 7/2002), Texas, Utah, Virginia (required by 7/2003), Wyoming. (Information provided by PTCB.)

91. Texas State Board of Pharmacy Rule \$291.29 http://www.tsbp.state.tx.us/Pharmacytechs.htm Accessed 2002 April 2

92. State of Utah, Division of Occupational and Professional Licensing. Pharmacy Practice Act. Available from Internet. http://www.dopl.utah.gov/ licensing/statutes_and_rules/58-17a.PDFAccessed 2002 April 2.

93. Alaska, Arizona, Kentucky, Massachusetts, Minnesota, North Carolina, Oregon, Tennessee, Texas, Virginia.

94. National Association of Boards of Pharmacy. Report of the NABP Committee on Law Enforcement/Legislation. Park Ridge, IL. 2000 Jan (Unpublished). Used with permission.

95. Activities which cannot be performed by a pharmacy technician: drug utilization review; clinical conflict resolution; prescriber contact concerning prescription drug order clarification or therapy modification; patient counseling; dispensing process validation; prescription transfer; and compounding.

96. Activities which cannot be performed by a certified pharmacy technician: drug utilization review; clinical conflict resolution; prescriber contact concerning prescription drug order clarification or therapy modification; patient counseling; dispensing process validation; receive new Prescription Drug Order when communicating telephonically or electronically unless the original information is recorded so the Pharmacist may review the Prescription Drug Order as transmitted.
97. Madigan M. Regulatory evolution of pharmacy technicians. Paper presented at PTEC Annual Meeting. Toronto, Canada; 2001 Jul 10.

98. Pharmacy Technician Certification Board. News Release NR\#02-001 Washington, DC: 2002 February 20. www.ptcb.org Accessed 2002 April 2.

99. Correspondence and personal communications between author and state board executives. 2001 Oct/Noy.

100. Shine KI, President of the Institute of Medicine. Address to the Institute's Annual Meeting.Washington, DC; 2000 Oct 17. http://www.iom.edu/IOM/ IOMHome.nsf/Pages/2000+IOM+President+Report Accessed 2002 April 2.

\section{APPENDIX: POLICY STATEMENTS OF NATIONAL ASSOCIATIONS}

The following are published with the permission of the respective organizations and are accurate as of March 2002, with the exception of (d), which is accurate as of June 2002.

a) The American Association of Colleges of Pharmacy: http://www.aacp.org/Docs/AACPFunctions/AboutAACP/4308_Cumulative Policies, 1980-2001.pdf Accessed April 2, 2002.

b) The American Association of Pharmacy Technicians: http://www.pharmacytechnician.com/

c) The American Pharmaceutical Association: www.aphanet.org

d) The American Society of Health-System Pharmacists: www.ashp.org See also http://www.ashp.org/public/hq/ Accessed 2002 April 4. See also http://www.ashp.org/public/hq/policy/2001PolicyPositions.pdf Accessed 2002 April 4.

e) The National Association of Chain Drug Stores: www.nacds.org

f) The National Community Pharmacists Association: www.ncpanet.org

g) The National Pharmacy Technician Association: http://www.pharmacytechnician.org/

h) The Pharmacy Technicians Educators Council: http://www.rxptec.org/ 